\title{
ESTÁGIO SUPERVISIONADO, VIA PARA A PESQUISA: RODAS DE CONVERSAS E NARRATIVAS DE EXPERIÊNCIAS
}

- MARIA LUISA FURLIN BAMPI

https://orcid.org/0000-0003-1919-0230

Universidade do Estado do Rio de Janeiro

MAIRCE DA SILVA ARAUJO

https://orcid.org/0000-0003-1434-7796

Universidade do Estado do Rio de Janeiro

O presente artigo tem como objetivo apresentar e analisar experiências vividas no cotidiano de estágio supervisionado realizado na Unidade Municipal de Educação Infantil (UMEI), vinculada à Faculdade de Formação de Professores (UFP) da Universidade do Estado do Rio de Janeiro (UERJ). A proposta teórico-metodológica do estudo é de natureza qualitativa com destaque à narrativa de experiências educativas como modalidade de formação de professores e como instrumento de coleta de informações, possibilitando entrecruzar formação e pesquisa a partir do estágio supervisionado, meta da proposta curricular. A seguir, faremos mensão aos temas apresentados à luz de alguns autores tomados como referência para darmos sentido às narrativas no contexto educativo: 1) contextualização do lócus de estágio; 2) o exercício de rememorar: uma oportunidade de educar o olhar; 3 ) roda de conversas: uma proposta de aprendizagem coletiva, que consistia da imersão na rotina da Educação Infantil; paralelamente, um encontro diário com a supervisão com as rodas de conversas, nas quais refletiamos sobre as memórias de vida por meio de fragmentos de memórias, elementos estruturantes das narrativas e instrumentos de pesquisa. As produções descritas dos diários de campo, fontes para as atividades de discussão, análise e pesquisa, contribuíram para compreender e atribuir significados à experiência humana no processo de formação docente.

Palavras-chave: Educação Infantil. Estágio Supervisionado. Pesquisa Narrativa. 
ABSTRACT SUPERVISED INTERNSHIP, PATH TO RESEARCH:

CONVERSATION WHEEL AND NARRATIVES OF

\section{EXPERIENCES AND NARRATIVES OF EXPERIENCES}

This article aims to present and analyze experiences lived in the daily Supervised Internship held at UMEI - Municipal Unit of Early Childhood Education, linked to UERJ-FFP. The theoretical and methodological proposal of the study is of a qualitative nature with emphasis on the narrative of educational experiences as a mode of teacher education and as an instrument for collecting information, enabling cross-training and research from the supervised internship, goal of the curriculum proposal. In the following we will discuss the themes presented in the light of some authors taken as reference to make sense of the narratives in the educational context: 1) Contextualization of the internship locus; 2) The exercise of remembering: an opportunity to educate the look; 3 ) conversation wheel: a proposal for collective learning, which consisted of immersion in the routine of early childhood education; at the same time, we had a daily meeting with the supervision of the conversation wheel, in which we reflected on life memories through fragments of memories, structuring elements of narratives and research instruments. The described productions of field diaries, sources for discussion, analysis and research activities, contributed to understand and assign meanings to the human experience in the process of teacher education.

Keywords: Early Childhood Education. Supervised Internship. Narrative Research.

\section{RESUMEN PRÁCTICA SUPERVISADA, CAMINO A LA INVESTIGACIÓN: RUEDAS DE CONVERSACIÓN Y NARRATIVAS DE EXPERIENCIAS}

Este artículo tiene como objetivo presentar y analizar las experiencias vividas en la práctica supervisada diaria realizada en UMEI - Unidad Municipal de Educación de la Primera Infancia, vinculada a UERJFFP; La propuesta teórico-metodológica del estudio es de naturaleza cualitativa, con énfasis en la narrativa de las experiencias educativas como un modo de formación docente y como un instrumento para recopilar información porque permite la capacitación cruzada y la investigación de la práctica supervisada, objetivo de la propuesta curricular. A continuación discutiremos los temas presentados a la luz de algunos autores tomados como referencia para dar sentido a las narrativas en el contexto educativo: 1) Contextualización del 
locus de práctica; 2) El ejercicio de recordar: una oportunidad para educar la mirada; 3) Hablar ruedas: una propuesta de aprendizaje colectivo, que consistió en la inmersión en la rutina de la Educación Infantil, en paralelo con una reunión diaria con la supervisión de las ruedas de conversación, en la que reflexionamos sobre: los recuerdos de la vida a través de fragmentos de recuerdos, elementos de estructuración de narrativas e instrumentos de investigación. Las producciones, escritas a partir de diarios de campo, fuentes de debate, análisis y actividades de investigación contribuyeron a comprender y asignar significados a la experiencia humana en el proceso de formación del profesorado.

Palabras clave: Educación de la Primera Infancia. Práctica Supervisada. Investigación Narrativa.

Iniciamos nosso artigo, que versa sobre a potência das narrativas de si como dispositivo de formação e investigação, com uma narrativa homenagem a uma grande companheira de caminhada que fez a sua passagem, repentinamente, sem que tivéssemos tempo para nos preparar para isso.

\section{Libertação}

Eu era uma criança de quem pouco se escutava a voz. Respeitosa das regras instituídas, mesmo em ocasiões nas quais a professora parecia desejar participação mais ativa, minha obstinação em ser obediente me levava a esperar a vez de falar com a mão pacientemente erguida no alto. Jamais tomaria a palavra sem que a mestra tivesse dado autorização expressa. - Pode falar, Jacqueline. É sua vez. Nestas ocasiões, com esforço de quem faz algo pouco praticado, projetava a voz um tanto mais que o normal, e me permitia responder a indagação da professora. - Muito bem. Resposta correta. Essa seria a minha alegria de menina tímida: ouvir da professora uma palavra de aprovação pública. Ser reconhecida por aquela figura de autoridade maior parecia dar sentido a minha presença em sala de aula, ao uniforme que usava, aos anos que teria pela frente ocupando carteiras enfileiradas, respondendo chamadas e realizando inacabáveis tarefas em cadernos de linhas pretas. Responder e acertar pareceria dar sentido a minha própria existência. Eu gostava de usar o uniforme escolar. Vestia com orgulho aquela composição de branco e azul, como uma honrosa distinção: "há muitas crianças que queriam poder usar camisa branca de tricoline e saia de tergal pregueada.", dizia minha mãe, com tom acusador, quando pressentia em meus olhos o desejo de gazetear uma aula. Resignava-me com um misto de culpa e alegria de não ser uma daquelas meninas sem escola. - Quem sabe responder? - intimou naquele dia a professora, depois de longa explicação sobre répteis e anfibios. Pela primeira vez não ergui de pronto a mão direita, esperando ser chamada em instantes pela educadora. Pela primeira vez não desejei mais que tudo na vida ser a aluna-boazinha que, esperando com paciência a vez de falar, mostra aos colegas como deve-se agir em sala de aula. Pela primeira vez experimentei, como num gesto de libertação, deixar meu olhar vaguear pelas paredes da sala, sem direção, sem motivo estritamente escolar. Não queria responder nada. Absolutamente nada. Queria tão somente o pequeno gesto da distância, se não do corpo, pelo menos da mente. Mas parece que naqueles tempos, o prazer da liberdade devia ser interditado às meninas boazinhas. - Responde, Jacqueline. Qual a diferença entre répteis e anfibios? Retornei minha atenção para a sala e para a professora, mas agora algo pareceria diferente. Sem saber muito porquê, e tomada de incomum coragem, um gesto nunca antes tentado, atirei o lápis no chão, gritando: - Não quero responder!! Come- 
çava ali minha paixão pela potência libertadora dos pequenos gestos infantis que rompem com formas de viver as normas e tradições. Começava ali meu desejo de ser professora da infância. (Jacqueline de Fatima dos Santos Morais, 2018) ${ }^{1}$

Uma amiga, parceira, militante, que acreditou sempre na urgência e na fertilidade da interlocução entre docentes latino-americanos, para fortalecer a luta por uma universidade pública, que em diálogo com a escola e com a comunidade, pudesse projetar uma educação igualitária, humanista e socialista.

Jacqueline Morais, presente! Agora e sempre!

\section{Puxando a conversa:}

[...] A maior parte da nossa memória está fora de nós, numa viração de chuva, num cheiro de quarto fechado ou no cheiro duma primeira labareda, em toda parte onde encontramos de nós mesmos o que a nossa inteligência desdenhara, por não lhe achar utilidade, a última reserva do passado, a melhor, aquela que, quando todas as nossas lágrimas parecem estancadas, ainda sabe fazer-nos chorar. Fora de nós? Em nós, para melhor dizer, mas oculta a nossos próprios olhares, num esquecimento mais ou menos prolongado. (PROUST, 2005, p. 172)

Este texto foi produzido tomando como base "as experiências pedagógicas tornadas narrativas" (PRADO, 2007, p. 52), "presentes" nos diários de campo de um grupo de estudantes do curso de Pedagogia, no decorrer do está-

1 Jacqueline de Fátima dos Santos Morais (1964-2019), foi professora associada da Faculdade de Formação de Professores (FFP), da Universidade do Estado do Rio de Janeiro (UERJ), por duas décadas. A narrativa com a qual the fazemos homenagem é parte de um livro, em processo de edição, organizado por dois coletivos docentes latino-americanos, que fazem investigação a partir da escola e da comunidade: Rede de Docentes que Narram sobre Infância, Alfabetização, Leitura e Escrita (Redeale), vinculado à FFP da UERJ e Rede desenredando Nudos (Redenu), localizado na cidade de Cajamarca, no Peru. A interlocução entre os grupos de docentes, da qual deriva a produção do livro, é fruto das ações investigativo-formativas, coordenadas por Mairce Araújo e Jacqueline Morais em parceria (ARAUJO e MORAIS, 2018). gio supervisionado, realizado em uma Unidade Municipal de Educação Infantil (UMEI). Experiências narradas e compartilhadas em rodas de conversa, que ao serem documentadas em diários de campo e em portfólios, puderam se constituir como matéria-prima para discussão, ressignificação e avaliação das práticas.

Lima, Geraldi e Geraldi (2015) dão suporte às nossas reflexões teórico-metodológicas quando definem "a narrativa de experiências do vivido, isto é, narrativas de experiências educativas" como uma modalidade de usos de narrativas na formação e na pesquisa em educação. Segundo os autores:

A especificidade dessa modalidade de pesquisa reside no fato de que o sujeito da experiência a narra para, debruçando-se sobre o próprio vivido e narrado, extrair lições que valham como conhecimentos produzidos a posteriori, resultando do embate entre a experiência e os estudos teóricos realizados após a experiência narrada. $(2015$, p. 11)

Em que sentido estamos articulando uma experiência em estágio supervisionado, curricular obrigatório e uma metodologia que é, ao mesmo tempo, um dispositivo de formação e de investigação, no campo educacional?

Explicitando nossa proposta pedagógica para o estágio curricular obrigatório apontamos como pressuposto que o estágio para nós:

[...] não é um tempo preparatório para a aprendizagem ou para a preparação do que pode vir a ser. Não é um ensaio para se chegar 'depois' a um lugar qualquer. Antes, um tempo em que o estudante e o cotidiano daquele lugar se enlaçam, se alteram, se misturam. (SILVA, 2011, p. viii)

Nessa perspectiva, nossa proposta de formação pensa o(a) professor(a) da infância, não como um/uma replicante de metodologias elaboradas por outrem, mas como um sujeito que reflete e se apropria do conhecimento em construção, um(a) investigador(a) da própria prática. 
Interessava-nos, portanto, no movimento vivido no estágio supervisionado favorecer condições para que as futuras professoras da infância, assumindo o lugar de sujeito da experiência, se debruçassem sobre o próprio vivido, narrando oralmente ou a partir dos registros no diário de campo, no, com e para o grupo. Nas rodas de conversa, buscávamos lições que pudéssemos extrair no processo de reflexão sobre a prática docente com os pequenos. A produção dos diários de campo tinha como propósito favorecer o "instalar-se numa prática concreta, de escrita, para pensar a si mesmo e se experimentar como sujeito da escrita" (SILVA, 2011, p. ix).

Nesse sentido, o movimento que buscamos viver com as graduandas no decorrer do estágio supervisionado, investia no processo narrativo, como possibilidade de articular processos de formação e investigação.

Os dados de pesquisa, que constituíram o material empírico para o presente artigo, foram compostos por narrativas retiradas dos diários de campo, dos portfólios das estudantes e pelos registros das rodas de conversa, produzidos pelas autoras, na condição de supervisoras do referido estágio. ${ }^{2}$

O diálogo entre as narrativas compartilhadas nas rodas de conversa e os textos de Benjamin, O narrador (1994), e Sobre o conceito de História (1994), que inspiraram algumas reflexões, reafirmaram a importância da narrativa para a proteção, conservação e ampliação das experiências vividas, tanto individuais quanto coletivas. As leituras do filósofo alemão nos

2 O estágio supervisionado aconteceu, conforme previsto na matriz curricular do curso, em horário e dia letivo, uma vez por semana, para o acompanhamento das atividades de estágio, pelas supervisoras, in loco. o grupo de alunas foi dividido em duplas, compondo uma por turma. Os relatos de estágio foram feitos individualmente nos diários de campo. No decorrer dos estágios, ocorria um horário de roda de conversa no final de cada dia para a leitura dos diários do estágio. Nesse momento, eram feitas as reflexões coletivas que contribuiram na formação e reflexão para a elaboração do portfólio, entregue no final do período. convidavam a desenvolver uma atenção sensivel sobre o processo vivido, já que as experiências "se perdem quando as histórias não são mais conservadas" (1994, p. 205). O autor nos instigava ainda a estarmos atentas aos pequenos acontecimentos, falas, expressões, sons, movimentos corporais ao referir-se à importância do papel do cronista que narra tanto os pequenos quanto os grandes acontecimentos, na medida em que ambos contribuem para uma compreensão mais ampla da realidade, pois "nada do que um dia aconteceu pode ser considerado perdido para a história" (BENJAMIN, 1994, p. 223).

O movimento da escrita, discutido e problematizado junto com o grupo, mobilizava a vivência de um processo que "aproxima e combina aquilo que viu, sentiu, percebeu, escutou e observou do vivido, com seu pensamento, suas lembranças, imaginação, de forma que extraia 'mais' sentido" (SILVA, 2011, p. x). Na leitura dos diários de campo, nas expressões, frases, citações, imagens, recortes foi emergindo uma narrativa que se revelava como uma atividade reflexiva e formadora, produtora de novos sentidos às experiências.

\section{Contextualizando o lócus de experiências do estágio}

O estágio supervisionado, com o qual dialogaremos aqui, aconteceu na UMEI Pastor Benedito Panisset, no primeiro semestre do ano de 2019, envolvendo estudantes do curso de Pedagogia da Faculdade de Formação de Professores (FFP), da Universidade do Estado do Rio de Janeiro (UERJ). A UMEI foi inaugurada no dia 21 de março de 2012 e localiza-se no bairro do Gradim, na cidade de São Gonçalo, estado do Rio de Janeiro, sendo parte da comunidade conhecida, localmente, como Morro da Salga.

Algumas informações levantadas por nós sobre a história da creche apontaram que a 
mesma representa uma conquista dos moradores da comunidade, que se organizaram em torno da reivindicação de uma creche no bairro, que atendesse às crianças de zero a cinco anos, tendo em vista que no local já havia uma escola pública que atendia às crianças do 10 ao 5o ano. A creche foi construída num espaço usado pelos moradores como serventia, porém, relatos orais sobre a escolha do local de construção também trazem histórias sobre disputas e deslocamentos de moradores que ali já se encontravam anteriormente. A UMEI recebeu o nome Pastor Benedito Panisset como homenagem a um antigo morador do bairro e pai da prefeita, em cujo mandato a creche foi construída.

A UMEI Pastor Benedito Panisset é bem localizada, possui uma boa estrutura física embora construída em dois pavimentos. As salas são amplas e arejadas, com capacacidade para 20 crianças e o berçário atende em média dez crianças. Além disso, possui uma secretaria, dois banheiros infantis, com instalações para banho de crianças: um masculino e um feminino; um banheiro de funcionários; uma cozinha; um refeitório; um depósito de merenda; uma lavanderia; uma guarita; e um depósito. No andar térreo, há um espaço muito apreciado pelas crianças contendo um ecorregador, uma casinha e uma gangorra. Por fim, há ainda um espaço arborizado, com terra, que fica na parte de trás do prédio, que tem sido subutilizado nos projetos da escola.

A UMEl atende a uma média de 95 crianças de um a cinco anos, organizadas em sete turmas, do berçário ao pré-escolar, com horário de funcionamento das $8 \mathrm{~h}$ às $17 \mathrm{~h}$. 0 quadro de profissionais da instituição contava com a seguinte equipe: uma diretora; um auxiliar de secretaria; uma orientadora pedagógica; uma orientadora educacional; 12 professoras; sete auxiliares de creche; cinco merendeiras; dois auxiliares de serviços gerais; dois inspetores de disciplina; dois porteiros; um vigia, totalizando 35 profissionais.

A dinâmica do estágio supervisionado consistia na presença do grupo uma vez por semana na creche, no horário das $8 \mathrm{~h}$ às $16 \mathrm{~h}$, sendo que devido ao desenho curricular previsto no curso, algumas estagiárias cumpriam o horário de $8 \mathrm{~h}$ às $12 \mathrm{~h}$, e outras de $12 \mathrm{~h}$ às $16 \mathrm{~h}$. “Tendo como proposta uma 'observação' que é, ao mesmo tempo, inserção, ação, relação, presença" (SILVA, 2011, p. viii). O estágio supervisionado vivenciado pelo grupo de professoras da infância em formação inicial, além do mergulho no cotidiano da instituição, também abrangia uma roda de conversa no final do turno, na qual eram compartilhadas as experiências, registradas no diário de campo e, ao final do semestre, comporiam o portfólio de cada estudante.

Em relação às narrativas escritas, o que incentivávamos era a produção de textos que não se configurassem como meros relatos informativos, pautados, ilusoriamente, pela linearidade e objetividade, demarcados pela cronologia dos fatos, mas que representassem registros de uma trajetória de formação, que deixasse entrever as marcas da experiência no sujeito que narra, entendendo que na perspectiva benjaminiana, a narrativa:

\section{[...] não está interessada em transmitir o puro em-si da coisa narrada como uma informação ou um relatório. Ela mergulha a coisa na vida do narrador para em seguida retirá-la dele. Assim se imprime na narrativa a marca do narrador, como a mão do oleiro na argila do vaso. (BENJA- MIN, 1994, p. 205)}

A partir de tais referências, dialogaremos com as narrativas produzidas pelas estagiárias, selecionando algumas que estão presentes no diário de campo e outras que foram compartilhadas nas rodas de conversa, por nós registradas em nossos apontamentos pessoais. 
Importante afirmar que o nosso olhar para o processo vivido com as estagiárias, também foi sendo provocado pelas nossas próprias memórias de professoras supervisoras e pesquisadoras do cotidiano escolar, memórias que a "inteligência desdenhara", como assinala Proust (2005) e que, fora de nós, nos despertavam para novas possibilidades de pensar a prática pedagógica.

Tendo assim caracterizado o espaço de intervenção, enquanto pesquisadoras no campo de supervisão e das narrativas de estágio, refletiremos sobre as vivências e as experiências que nos constituíram.

\section{O exercício de rememorar: uma oportunidade de educar o olhar...}

A expressão reta não sonha.

Não use o traço acostumado.

A força de um artista vem das suas derrotas.

Só a alma atormentada pode trazer para a voz um formato de pássaro.

Arte não tem pensa:

O olho vê, a lembrança revê, e a imaginação transvê.

É preciso transver o mundo.

Manoel de Barros (2000, p. 75)

A primeira atividade desenvolvida com o grupo de estágio foi uma dinâmica de reflexão sobre a memória. Para tal fizemos a leitura da história do livro Guilherme Augusto Araújo Fernandes. A atividade aludia à história de uma senhora, Dona Antonia, que mora em um asilo e perdeu a memória e de um garoto, Guilherme, que mora ao lado do asilo que, preocupado com a perda da memória da amiga, se desafia a ajudá-la recuperar suas memórias. Os dois personagens centrais da história estavam separados apenas por uma pequena cerca. No encontro das memórias do velho e da criança, os tempos se presentificavam, as relações se atravessavam, se tangenciavam... mobili- zando no grupo, a experiência benjaminiana que "passa de pessoa em pessoa" (BENJAMIN, 1994, p. 198). Guilherme vai em busca das próprias memórias para "despertar" as memórias de Dona Antonia. Assim, aprendendo com os outros moradores do asilo, sobre o que é memória, vai colecionando uma série de objetos que para ele representem "algo que você se lembre, algo quente, algo bem antigo, algo que o faz chorar, algo que o faz rir, algo que vale ouro..." Recolhe objetos-memória e oferece para a senhora, que a partir do encantamento provocado pelos presentes de Guilherme, "recupera" sua memória. Provocadas pelas memórias de Guilherme o grupo produziu suas narrativas:

[...] Fiz uma xícara de café. Esta liga minha memória ao passado e está diretamente ligada ao presente.

Minha infância foi muito feliz. Em especial acerca do café, me lembro como minha bisa gostava de café com leite, assim como: minha avó, meu pai, minha irmã, mãe, eu e minhas filhas. Me lembro quando pequena ver a minha bisa tomar café com leite antes de dormir e de como isso acaba hoje sendo algo que faz parte do meu cotidiano. Sendo café puro ou café com leite, eu amo!!

Memórias que para mim são: Doces, quentinhas, alegres, tristes e que deixam muitas saudades pela perda de algum desses amados. (Diário de Campo, Monique, 2019, p. 1)

Chamamos Benjamin (1994, p. 49) para relacionar a teoria estudada à experiência que ilustra a possibilidade de revisitar os momentos vividos por meio das recordações em imagens, odores e sabores:

[...] dos momentos da reminiscência, não mais isoladamente, com imagens, mas informes nãovisuais, indefinidos e densos, anunciam-nos um todo, como um peso da rede anuncia sua presa ao pescador. 0 odor é o sentido do peso, para quem lança a rede no oceano do temps perdu (grifo do autor). 
Uma xícara. Como não ressaltar a importância da memória despertada pelo cheirinho de café, servido no horário de chegada à creche, que possibilita revisitar o passado? É possivel constatar que os fatos rememorados e representados por uma xícara têm muito a nos dizer sobre a experiência de cada um de nós e colocar em evidência que a memória pode ser acessada por fatos e artefatos da vida cotidiana e que os mesmos podem despertar nossas mais profundas emoções de amor, de tristeza, perda etc.

As reflexões provocadas pelos compartiIhamentos na roda de conversa, registradas no diário de campo evidenciam o significado da memória e as possibilidades de serem acessadas, como revela Proust (2005) na epígrafe do texto.

[...] A professora perguntou o que é uma memória? Meu entendimento, é que cada um tem uma percepção e uma experiência do que é memória. Pelas experiências as memórias são construídas e nos fazem, depois de anos vividos, relembrar fatos que aparentemente foram esquecidos, mas quando em momentos do nosso cotidiano afloram, trazem a inesquecivel lembrança que nos marcou, e a convicção de que estava só guardada e não totalmente esquecida. (Diário de Campo, Monique, 2019, p. 1)

Enquanto íamos dialogando sobre os múltiplos sentidos que o processo de rememoração provocava em nós, a partir da história de Guilherme Augusto, novas lembranças iam sendo compartilhadas por meio de poemas, desenhos, dobraduras, inspiradas nas memórias quentes, antigas, tristes, alegres, que valiam o ouro do menino e envolviam a todas nós:

[...] tecendo uma rede que em última instância todas as histórias constituem entre si. Uma se articula na outra, como demonstraram todos os outros narradores, principalmente os orientais. Em cada um deles vive uma Sherazade, que imagina uma nova história em cada passagem da história que está contando. (BENJAMIN, 1994, p. 211)
Disparadas e provocadas por todo o contexto de produção, emergiam memórias de infância nas diferentes narrativas orais, escritas, pictóricas, que possibilitando ao grupo transver os próprios olhares sobre as crianças que fomos, nos convidavam a construir novos olhares para as crianças com as quais estávamos interagindo no espaço da UMEI.

Memórias confeccionadas revelavam os rastros daquilo que ficou, a experiência, do tempo vivido na educação infantil pelas participantes do grupo. Por sua vez, as narrativas de tais experiências, dando a ver os modos de conceber a escola, as professoras, as relações adultos-crianças, tornavam-se uma forma potente de formação e de autoformação. Movimento evidenciado no processo de relacionar a experiência e os estudos teóricos realizados após a experiência narrada, mobilizando a construção de uma perspectiva outra para pensar a futura atuação docente.

As rememorações das experiências, a matéria-prima da reflexão teórica proposta, nos remetem à distinção das categorias conceituais de experiência e vivência em Benjamin (1994). O autor assinala vivência - Erlebnis - como uma ação/reação que se esgota no momento de sua realização, por isso finita, enquanto que a experiência - Erfahrung - refere-se ao vivido que é pensado e narrado; uma ação que é contada a um outro, compartilhada, portanto, coletiva e infinita, apresentando um caráter histórico, de permanência, de ir além do tempo vivido. Diante disso, revelar uma experiência significativa representa mais que a ressignificação do já vivido, mas a experiência do passado rememorada traz os rastros do passado, entretanto, revivida e inserida pela perspectiva da atualidade. Desse modo, reinventada ou mesmo, transvista, como nos ensina, Manoel de Barros (2000, p. 75): “O olho vê, a lembrança revê, e a imaginação transvê. É preciso transver o mundo." 
No exercício de pensar sobre o olho que vê, nas lembranças que nos provocam a rever e no papel da imaginação que nos leva mais longe, nos debruçamos sobre os registros dos diários de campo, nos quais os fragmentos das narrativas, imagens, desenhos, pinturas, fotografias compunham uma obra de múltiplos matizes. Percebíamos que, para além do relatado, havia uma linguagem/expressão entretecida nas lembranças, memórias, brancos, lapsos... Aspectos esses apresentados nas rodas de conversas e nos registros que nossas futuras professoras foram "pintando" no quadro/diário e que se apresentam por meio das narrativas estéticas e das "múltiplas vozes e imagens que as constituem" que serão pontuadas a seguir.

\section{Roda de conversas: uma proposta de aprendizagem coletiva}

Nas quartas-feiras de manhã, por vezes no horário de chegada, e antes da entrada das crianças, era possivel compartilhar alguns fatos e analisá-los coletivamente. Contudo, no horário que antecedia a saída estava marcado o "momento de encontro" do grupo na sala dos professores: as rodas de conversa. Nesse espaço, voluntariamente eram lidas e analisadas algumas narrativas das observações individuais feitas em sala de aula. Cada leitura de narrativas de experiências escritas revelava os "recortes de olhares" de "cada um" e os diversos "outros" em uma mesma vivência simultânea, que era narrada por cada uma das duplas de estágio. Essas evidências dispararam os momentos de reflexão e análise coletiva. Tal prática fundamenta-se na concepção de que as narrativas de vida possibilitam outras maneiras de conceber as práticas educativas e de supervisão de estágio.

Rosa (2011) inspirou-se nas teses de Benjamim (1994) e afirma que por meio das narra- tivas é possivel ir construindo o presente por meio das marcas das memórias:

[...] ressignificação no fazer do cotidiano a própria experiência, na relação entre o eu e o outro, nos acontecimentos que nos deixam marcas de experiências vividas e não apenas vivências sem experiências, através de memórias conscientes e inconscientes cheias de significados, sentimentos e sonhos. (ROSA et al., 2011, p. 202)

$\mathrm{O}$ ato de narrar o presente texto nos levou também a cotejar sobre o olhar da supervisão, ou seja, nosso próprio olhar. Somos levadas a perceber que as nossas propostas de educação e supervisão, enquanto espaço de investigação, são constituídas na necessidade de refletir a respeito da perspectiva de educar, refinando o olhar, despertando-nos para a possibilidade de não apenas ver, mas de transver o que estava sendo narrado no grupo.

A atividade pedagógica que ponderou sobre o olhar foi a leitura e meditação do texto de Silva (2011), intitulado "Entre estágios, diários de campo, leituras", que reflete sobre o período/campo de estágio como uma oportunidade de ir além do ver e educar e refinar o olhar. Tal escolha certamente deve-se às emoções evocadas, uma vez que as experiências geraram muitas surpresas e angústias, e assim, a pedagogia do olhar foi se construindo.

O registro de Conceição, (2019, p. 2), em diálogo com os objetivos da proposta de produção do diário de campo, nos permite perceber o movimento de autorreflexão da autora, nos verbos que costuram sua narrativa: reavaliar, ressignificar, reconstruir:

[...] O relatório tem por objetivo reavaliar o nosso olhar para as crianças e o estágio é uma grande oportunidade para educá-lo, pois todas as crianças são diferentes umas das outras. [...] ressignificar memórias ou reconstruir muitos dilemas, conceitos, ideias, que pude perceber que não era o melhor para que eu oferecesse para meus futuros educandos. (Diário de Campo, Conceição, 2019, p. 2) 
Evelyn em sua narrativa diz:

[...] Vivemos e trocamos experiências, afetei e fui afetada por aqueles sujeitos, que tão pequenos já conseguem ver e ler o mundo de uma forma tão fascinante, e tudo que eu precisei fazer foi me permitir viver mais essa experiência que a vida pode me proporcionar. (Diário de Campo, Evelyn, 2019, p. 12)

Um adulto que se permite afetar pelos pequenos, que se abre para que as experiências de leitura de mundo das crianças provoquem outras leituras possiveis. Futuras professoras das infâncias que se deparam com um sujeito produtor de cultura, que até então não conheciam, possivelmente, por terem sido atravessadas por referenciais que enxergam a criança e a infância como um devir, como um espaçotempo de preparação para o futuro.

No diálogo entre as narrativas de Conceição e Evelyn, vamos percebendo o movimento de mudança de olhar que pretendíamos como proposta das rodas de conversa.

Esse movimento de reavaliar, ressignificar, reconstruir também aparece em outros diários de campo, indicativos da potência tanto do exercício de produção escrita, quanto da reflexão coletiva que se dava nas rodas de conversa.

Jéssica (2019, p. 4) traz em seu diário suas leituras da experiência vivida no estágio à luz das reflexões teóricas construídas no grupo de pesquisa do qual faz parte:

[...] Faço parte de um grupo de pesquisa e em uma das discussões falávamos sobre o que queremos ver nas escolas. A professora Inês Barbosa dizia que veremos sempre o que quisermos ver. Se chegarmos querendo ver falhas a veremos sim, mas se decidirmos olhar as potências do lugar, acreditando que elas existem ali, assim a veremos. Ela usou a frase 'precisamos crer para ver', como diz Alves (2008, p. 18). (Diário de Campo, Jéssica, 2019, p. 4)

Mais adiante, a autora supracitada traz um registro em seu diário de campo sobre o estranhamento que viveu durante a roda de con- versa ao ouvir de sua dupla a narrativa de um episódio, que acontecera na sala em que estagiava.

[...] Eu estava na mesma sala no mesmo momento e não reparei! Pude refletir e perceber que o olhar é assim e que no momento de escrever cada uma de nós 'escolhe fragmentos do cotidiano, os edita, os arranja...' Fiquei pensando que um dia no momento de leitura, seria interessante ouvirmos a leitura de dois diários das meninas que estão na mesma sala. (Jéssica, narrado em 17/04/2019)

\section{Fragmentos de memórias ou narrativas de si?}

Nas reflexões aqui apresentadas, não há a pretensão de fazer distinção entre as narrativas dos diários de campo, memoriais de formação de professores, portfólio, e tantas outras designações dadas à narrativa de experiência aqui trazidas. No diálogo com as narrativas presentes nos diários e nos portfólios, buscamos refletir sobre a importância desses instrumentos de pesquisa e as possibilidades de construção e reconstrução de si que decorrem dessas práticas, quando a posteriori são descritas e refletidas como refere Nòvoa (1988).

Apresentamos os fatos narrados nos diários de campo do estágio em Educação Infantil e o percurso de vida construído pelas estagiárias se fazendo presente em suas narrativas. Cada narrativa constitui um fio condutor de uma memória da infância presente nas problemáticas ou na centralidade problemática refletida no presente sendo narrado e rememorado.

Como indica Prado e demais autores (2015), na pesquisa narrativa, o narrador, no presente, evoca memórias e seu texto configura-se em fatos passados que se entrelaçam com presente, de tudo o que viu, ouviu, viveu e aprendeu:

[...] Um texto em que o autor faz um relato de sua vida procurando apresentar acontecimen- 
tos a que confere o status de mais importantes ou interessantes no âmbito de sua existência. 0 narrador ao lembrar do passado o faz no presente, sendo assim suas lembranças são evocações de memória que se configuram em um entrelaçamento das recordações de vivências trabalhadas no presente com as múltiplas vivências e informações que foram se somando a sua existência. (PRADO et al., 2015, p. 6)

A proposta de aprendizagem coletiva por meio das atividades de leitura e reflexão no e com o cotidiano escolar, somada às reflexões sobre os textos que leram e se inspiraram para compor as narrativas de estágio, pode ser entendida como um espaço de formação coletiva que contribui para o desenvolvimento dos saberes docentes e sua formação profissional.

Quando a escrita é produzida para ir além de seu tempo, ela permite que aquele que escreve a viva como experiência. Um processo em que o sujeito se aproxima e combina aquilo que viu, sentiu, percebeu, escutou e observou o vivido, com seu pensamento, suas lembranças, imaginação, de forma que extraia 'mais' sentido. Uma escrita que é formativa. (SILVA, 2011, p. x)

Uma escrita que vá além de seu tempo, seria a narrativa de Samira, quando fala sobre a experiência do estágio a partir da conhecida música de Raul Seixas "Metamorfose ambulante".

Acho que o que mais define esse meu antes e depois, que ainda está em fase de construção é a letra da música de Raul Seixas, 'Metamorfose ambulante', sempre que penso nessa letra quando começo a refletir sobre quem eu era, quem eu sou e quem eu estou construindo para o meu futuro. (Diário de Campo, Samira, 2019, p. 3)

Não estaria Samira revelando lampejos de consciência de si provocados pela escrita reflexiva das experiências vividas no estágio? Sua análise não está presa ao apenas vivido naquele espaço-tempo, às atividades realizadas com as crianças, às trocas com as companheiras de turma. Envolve tudo isso, mas vai além, ajuda a se repensar como um sujeito da vida, uma professora da infância, em permanente formação: aberta a muitas "metamorfoses ambulantes".

Desejamos com ela: qual horizonte de possibilidades projeta em seu futuro? Esperamos que seja o do questionamento, da busca, da formação entre pares e da autoria.

Em consonância com Lima e demais autores (2015), pudemos perceber que nas narrativas da experiência vivida, produzidas pelas futuras docentes foram trazidos referenciais teóricos para o diálogo e que, por sua vez, fazem emergir as lições de vida e profissionais.

0 registro de Jéssica sobre a observação feita em classe reedita a visão da escola como espaço de "domesticação de corpos":

[...] a pressão sobre as crianças de 4 anos ficarem sentadas em suas carteiras com cabeças abaixadas para esperar os pais chegarem. A linguagem corporal da criança desta maneira era bastante rejeitada com intuito de preservar um ambiente calmo e silencioso. Além de atividades monótonas de cobrir pontinhos, que eram consideradas como atividade psicomotora. (Diário de Campo, Jéssica, 2019, p. 3)

Evidenciando-se no relato a escola e sua arquitetura de poder, cuja lógica ainda é formar corpos dóceis, individualizando-os, transformando-os em máquinas, em busca de garantir o homem educado para um modelo de sociedade, como estudou Foucault (2002), ainda mantém suas fortes referências no cotidiano escolar, desde a educação infantil. Por outro lado, em relação às questões de normatização e controle, à narrativa de Letícia, outra narrativa complementa suas ideias e evidencia que onde há relações de poder, também se encontram pontos de resistência ou brechas.

[...] mesmo com esse caráter regulador que a escola se apresenta, as crianças parecem se divertir muito entre si. Já introjetaram, desde a creche, a forma que a escola acredita e ensina que elas devem se comportar. (Diário de Campo, Letícia, 2019, p. 5) 
Em consonância com a proposta de Santos (1987, p. 48), "precisamos de procedimentos de pesquisa que se dediquem a encontrar experiências exemplares a serem multiplicadas". Em nosso trabalho, buscamos nos saberes da prática educativa concreta ouvir as vozes e entrever saberes/fazeres de professoras e futuras professoras da infância, reconhecendo nesses saberes/fazeres características qualitativas e possibilidades de uma autoformação coletiva e ampliada. A marca dessa autoformação coletiva se revela em uma citação que aparece em vários diários de campo: "o sujeito da escrita, embora individual, é sempre coletivo" (Silva, 2011, p. ix).

Samira assinala o papel do coletivo no processo de formação:

Nada mais sou do que a escriba dessas construções, que foram construídas com as crianças, com as professoras, as auxiliares, minhas colegas de turma e minhas professoras. (Diário de Campo, Samira, 2019, p. 3)

Escrever, narrar as próprias experiências, é também escrever-se, narrar-se. Essa foi uma das descobertas de Samira, que ao debruçarse sobre a experiência vivida no cotidiano, viuse no movimento de busca de si mesma.

[...] pensar em como todas essas situações me atravessaram, me possibilitou com a autorização das professoras, desenvolver uma atividade onde a abordagem do reconhecimento identitário foi o tema norteador. A situação que instigou a minha intervenção pedagógica foi quando a criança negra se desenhou com características fisicas de uma criança branca e loira e disse que aquela era ela. A questão do não autorreconhecimento étnico-racial, infelizmente acontece nos cotidianos escolares, no qual, em um currículo eurocêntrico, o papel do índio e do negro ainda são relegados à de subalternidade e à escravidão. Por vivermos em um país com um grau elevado de miscigenação, às vezes tentamos apagar da nossa história as origens desses povos. Em nosso currículo cotidiano a ideologia do embranquecimento é afir- mada todos os dias, seja em uma aula de português onde só lemos autores brancos, ou em uma aula de matemática, onde apenas a matemática ocidental é afirmada como legítima. (Diário de Campo, Samira, 2019, p. 4)

Perceber na atitude da criança negra em desenhar-se branca um processo de construção de subjetividades subalternizadas produziu em Samira um atravessamento, sobre o qual nos fala Larrossa (2016), ao definir a experiência como algo que nos atravessa. Ao sentir-se atravessada, foi desafiada também a responder ao incômodo que se instalara: Como eu me vejo? Como vejo as pessoas a minha volta? Um incômodo que gerou o planejamento de uma atividade que pudesse contribuir para provocar novos olhares da criança sobre si mesma. O livro de literatura infantil $O$ cabelo de Lelê foi o dispositivo escolhido:

O objetivo era de conhecer a diversidade física, estética e racial. Materiais espelho para se verem e se desenharem. Perguntas sobre o cabelo de Lelê. Como são os olhos, cabelos, e desenharem o que viram no espelho... Improviso. (Diário de Campo, Samira, 2019, p. 4)

Por onde passa a formação da professora -pesquisadora? Se os caminhos são múltiplos e apostamos que sim, nossa experiência com o estágio reafirmou a centralidade da escola e da reflexão coletiva nesse processo.

\section{Partes de nós se revelam nos escaninhos de nossas memórias: alguns apontamentos finais}

O estágio supervisionado na educação infantil desenvolvido no contexto educativo apresentado nos diários de campo, nas rodas de conversas e, posteriormente, na construção dos portfólios, nos ofereceu um material rico de pesquisa e reflexão, trazendo-nos evidências da importância do estágio supervisionado como um campo de pesquisa e investigação. 
Narrar os pequenos eventos cotidianos, vividos no espaço-tempo do estágio supervisionado, buscando as lições que poderiam nos trazer, sobre os processos de formação da professora da infância, também nos permitiu produzir uma escrita sobre esses acontecimentos, que buscam ir além do tempo vivido e configurar-se como um processo formativo que nos fortalece enquanto sujeitos que pensam sobre sua prática.

O uso da narrativa enquanto instrumento metodológico se apresentou como um meio de aprendizagem e também de investigação, na medida em que nos ofereceu uma forma de articular o conhecimento cotidiano da prática da sala de aula, com as construções e constituições pessoais e as perspectivas profissionais, fornecendo-nos uma base para a reflexão crítica sobre a experiência pedagógica e enquanto promotora de conhecimentos nesta e noutras investigações.

A escrita promove a aprendizagem no sentido em que coloca em diálogo conhecimentos práticos e pessoais com a reflexão sobre as práticas, pois, quando os eventos passados são apresentados pela perspectiva - do narrador - essa visão, a posteriori daquilo que ocorreu, é conectada com novos saberes conhecimentos já construídos e promovendo saberes sempre novos, como refere Benjamin (1994).

Enfim, as narrativas de estágio supervisionado aqui construídas representam também um ensaio no sentido de autoformação. Como referem Prado e demais autores (2015, p. 102), “escrever é fazer história: revelações, superações, subversões que mobilizaram a experiência e representam o ato de reviver através da escrita", de rememorar e refletir a partir das lembranças a produção de sentidos que as práticas de leituras de diários de campo, as rodas de conversa, e o compartilhamento de ideias provocaram em nós.

\section{Referências}

ARAUJO, Mairce da Silva, MORAIS, Jacqueline de Fátima dos Santos. Brasil-Peru nas dobras do (im) possivel: compartilhando experiências no diálogo entre coletivos docentes. In: ARAUJO, Mairce da Silva, MORAIS, Jacqueline de Fátima dos Santos (orgs) Brasil-Peru: experiências educativas a partir de uma expedição pedagógica. São Carlos: Pedro \& João Editores, 2018. p. 23-35.

BARROS, Manoel de. Livro sobre nada. Rio de Janeiro: Record, 2000.

BELEM, Valéria. Cabelo de Lelê. Ilustrações Adriana Mendonça. São Paulo: Companhia Editora Nacional, 2007.

BENJAMIN, Walter. O Narrador. In: BENJAMIN, Walter. Obras escolhidas. Magia e técnica, arte e política. 7a. Ed. São Paulo: Brasiliense. 1994. p. 197-221

BENJAMIN, Walter. Sobre o conceito de história. In: BENJAMIN, Walter. Obras escolhidas. Magia e técnica, arte e política. 7ạ. Ed. São Paulo: Brasiliense. 1994. p. 222-232.

FOUCAULT, Michel. Vigiar e punir. Tradução de Raquel Ramalhete. Petrópolis, RJ: Vozes, 2002.

KRAMER, Sonia; NUNES, Maria Fernanda Rezende; CORSINO, Patricia. Infância e crianças de 6 anos: desafios das transições na educação infantil e no ensino fundamental. Educação e Pesquisa, São Paulo, v. 37, n. 1, 220p. 69-85, jan./abr. 2011. Disponível em: http://www.revistas.usp.br/ep/article/ view/28272/30114. Acesso em: 12 ago. 2019.

LARROSSA, Jorge. Tremores: escritos sobre experiência. Belo Horizonte: Autêntica, 2016.

LIMA, Maria Emília Caixeta de Castro; GERALDI, Corinta Maria Grisolia e GERALDI, João Wanderley. O trabalho com narrativas na investigação em educação. Educação em revista. vol. 31, n.1, p.17-44, 2015. Disponivel em: http://www.scielo.br/pdf/edur/ v31n1/0102-4698-edur-31-01-00017.pdf. Acesso em: 30 set. 2019.

NÒVOA, A.; FINGER, M. 0 método (auto)biográfico e a formação. Lisboa, MS/DRHS/CFAP, 1988. 
PRADO, Guilherme Val Toledo e SOLIGO, Rosaura. Memorial de formação: quando as memórias narram a história de Formação. In: PRADO, Guilherme Val Toledo e SOLIGO, Rosaura (Org.). Porque escrever é fazer história: revelações subversões e superações. 2.ed. Campinas: Alínea, v.1, 2007, p. 45-60.

PRADO, Guilherme do Val Toledo; SERODIO, Lena Arrais; PROENÇA Heloisa Helena Dias Martins; RODRIGUES, Nara Caetano (Org.). Metodologia Narrativa de pesquisa em educação: uma perspectiva bakhtiniana. São Carlos: Pedro e João Editores, 2015.

PROUST, Marcel. A sombra das raparigas em flor. São Paulo: Globo, v. 2. 15a ed., 2005.

ROSA, Maria Inês Petrucci; RAMOS, Tacita Ansanello; CORRÊA, Bianca Rodrigues; JUNIOR, Admir Soares de Almeida. Narrativas e mônadas: potencialidades para uma outra compreensão de currículo. Currículo sem Fronteiras, v. 11, n. 1, p. 198-217, 2011. Disponivel em: http://www.curriculosemfronteiras. org/vol11iss1articles/rosa-ramos-correa-junior.pdf. Acesso em: 5 jun. 2019.

SANTOS, Boaventura de Sousa. Um discurso sobre as ciências. Porto: Edições Afrontamento, 1987.

SILVA, Lilian Lopes Martin da. Entre estágios, diários de campo, leituras. In: Vários autores. Culturas infantis em creches e pré-escolas: estágio e pesquisa. Campinas: Autores Associados, 2011. p. vii-xi.

SOUZA, Elizeu Clementino de. $\mathbf{O}$ conhecimento de si: narrativas do itinerário escolar e formação de professores. 2004, $344 \mathrm{f}$. Tese de Doutorado, Programa de Pós-Graduação em Educação, Universidade Federal da Bahia, Salvador. 2004. Disponível em: https://repositorio.ufba.br/ri/bitstream/ri/10267/1/ Tese_Elizeu\%20Souza.pdf. Acesso em: 5 abr. 2019.

Recebido em: 29/10/2019 Revisado em: 29/07/2020 Aprovado em: 04/08/2020

Maria Luisa Furlin Bampi é mestre em Psicologia Escolar Pontifícia Universidade Católica de Campinas (PUC-Campinas) e doutora pela Universidade de São Paulo (USP). Professora assistente no Departamento de Educação da Faculdade de Formação de Professores (FFP) da Universidade do Estado do Rio de Janeiro (UERJ). Faz parte dos grupos de pesquisas Vozes da Educação: memórias, histórias e formação docente e do Abordagem histórico-cultural e práticas sociais da Universidade Federal Fluminense (UFF).E-mail: luisa.bampi@uol.com.br

Mairce da Silva Araujo é mestre em Educação pela Universidade Federal Fluminense (UFF) e doutora em Educação pela Universidade Federal do Rio de Janeiro (UFRJ). Professora associada da Faculdade de Formação de Professores (FFP), da Universidade do Estado do Rio de Janeiro (UERJ). Procientista. Professora permanente do Programa de Pós-graduação em Educação: processos formativos e desigualdades sociais. Vice-líder do grupo de pesquisa Vozes da Educação: memórias, histórias e formação docente; coordenadora do grupo de pesquisa Alfabetização, Memória, Formação de professores e Relações Etnicorraciais (Almefre).E-mail: mairce@hotmail.com 